\title{
Snow accumulation distribution inferred from time-lapse photography and simple modelling
}

\author{
Daniel Farinotti, ${ }^{1 *}$ Jan Magnusson, ${ }^{2}$ Matthias Huss ${ }^{1,3}$ and Andreas Bauder ${ }^{1}$ \\ ${ }^{1}$ Laboratory of Hydraulics, Hydrology and Glaciology (VAW), ETH Zurich, 8092 Zurich, Switzerland \\ ${ }^{2}$ WSL Institute for Snow and Avalanche Research (SLF), 7260 Davos Dorf, Switzerland \\ ${ }^{3}$ Department of Geosciences, University of Fribourg, 1700 Fribourg, Switzerland
}

\begin{abstract}
:
The spatial and temporal distribution of snow accumulation is complex and significantly influences the hydrological characteristics of mountain catchments. Many snow redistribution processes, such as avalanching, slushflow or wind drift, are controlled by topography, but their modelling remains challenging. In situ measurements of snow accumulation are laborious and generally have a coarse spatial or temporal resolution. In this respect, time-lapse photography shows itself as a powerful tool for collecting information at relatively low cost and without the need for direct field access. In this paper, the snow accumulation distribution of an Alpine catchment is inferred by adjusting a simple snow accumulation model combined with a temperature index melt model to match the modelled melt-out pattern evolution to the pattern monitored during an ablation season through terrestrial oblique photography. The comparison of the resulting end-of-winter snow water equivalent distribution with direct measurements shows that the achieved accuracy is comparable with that obtained with an inverse distance interpolation of the point measurements. On average over the ablation season, the observed melt-out pattern can be reproduced correctly in $93 \%$ of the area visible from the fixed camera. The relations between inferred snow accumulation distribution and topographic variables indicate large scatter. However, a significant correlation with local slope is found and terrain curvature is detected as a factor limiting the maximal snow accumulation. Copyright $($ C 2010 John Wiley \& Sons, Ltd.
\end{abstract}

KEY WORDS snow accumulation; time-lapse photography; precipitation modelling

\section{INTRODUCTION}

When studying characteristics of Alpine catchments, snow is an important component. It can strongly increase the albedo of a surface, reduce its roughness, insulate the underlying ground from the atmosphere and store or release large amounts of water (Essery et al., 1999). In Alpine environments, snow cover dynamics often dominate water resource formation, storage and release (Lehning et al., 2006). Modelling the snowpack and its evolution is thus of interest for a wide range of applications, including flood and avalanche forecasting or simulations of effects caused by climate change. However, modelling solid precipitation in the Alps is challenging. The Alpine chain modifies the structure of overlying synoptic systems through cyclogenetic processes (e.g. Mesinger and Pierrehumbert, 1986), and the effect of complex patterns of mountain ridges and valleys modulates the distribution of precipitation via orographic upslope lifting and the development of local mesoscale circulations (Wallén, 1970). At smaller scales, the precipitation distribution is affected considerably by local topographic effects (e.g. Spreen, 1947; Basist et al., 1994). As a result, snow accumulation in mountainous terrain is complex.

* Correspondence to: Daniel Farinotti, Laboratory of Hydraulics, Hydrology and Glaciology (VAW), ETH Zurich, 8092 Zurich, Switzerland. E-mail: farinotti@ vaw.baug.ethz.ch
The most important topographic factor controlling the amount of deposited snow is elevation (e.g. Seyfried and Wilcox, 1995). The strong altitudinal gradient is due to the relation between altitude and both, temperature and precipitation. Once on the ground, snow undergoes a variety of redistribution processes, such as wind drift (e.g. Kind, 1981; Dadic et al., 2010), avalanching and slushflow (e.g. Luckman, 1977). The resulting snow distribution patterns are often similar over time due to the topographic control of the redistribution processes (e.g. Elder et al., 1991; Luce et al., 1998).

Many approaches exist to model wind drift processes (e.g. Schmidt, 1986; Liston and Sturm, 1998), some of them achieving a high grade of process detail description, such as particle-bed collisions, particle motion and particle-wind feedback (e.g. Doorschot et al., 2001; Nemoto and Nishimura, 2004; Lehning et al., 2008). However, precipitation modelling is often only one component of a more complex model, for instance, one aiming at hydrological analysis (e.g. Schaefli et al., 2005; Lehning et al., 2006). In such cases, simpler and computationally cheaper approaches are appreciated.

Although information on the snow cover is often available at high temporal resolution from automatic stations at individual points (Egli, 2008), the spatial resolution of this information is generally coarse. In situ measurement of snow accumulation with high spatial resolution is very costly in terms of time, manpower and expense. For 
this reason, considerable effort has focused on developing methods for estimating the distribution of snow properties from remotely sensed data (e.g. Dozier and Painter, 2004; Machguth et al., 2006). Microwave remote sensing has shown promise for evaluating different properties, including snow depth and snow density (Shi and Dozier, 2000a; Shi and Dozier, 2000b). A review of methods developed for measuring snow and glacier ice properties through satellite remote sensing was presented by König et al., (2001).

The idea of inferring snow accumulation distribution from the observed melt-out pattern has been presented before in different studies (e.g. Martinec and Rango, 1981; Davis et al., 1995; Turpin et al., 1999) but often the observed snow cover evolution was used for the validation of distributed melt models only (e.g. Leavesley and Stannard, 1990; Blöschl et al., 1991; Mittaz et al., 2002). Moreover, in all mentioned studies, the evolution of melt-out was observed by either satellite or aerial photography, which are relatively expensive sensors, not easy to operate, and generally with a low temporal resolution.

In comparison, conventional photography can be a powerful tool for collecting information in an easy way and at relative low cost (Corripio, 2004). If the information is referenced precisely in space, photography becomes a valid tool for quantitative analysis. Such applications are well developed in photogrammetry but not in conventional photography.

In this paper, we combine the pictures taken during a melt-out season by a fixed conventional photographic camera with a distributed melt and accumulation model to infer the snow accumulation distribution in a small catchment in the Swiss Alps. The inferred distribution, which is assumed to be constant over time, is then used to build up the snow cover during one winter season. The resulting end-of-winter snow water equivalent (SWE) distribution is validated against direct snow depth measurements, and the distribution of the parameter controlling the snow accumulation is correlated with topographic variables.

\section{STUDY SITE AND DATA}

Our analyses are performed in the Alpine catchment of Dammagletscher, in the central Swiss Alps (Figure 1). The catchment had a glacierization of $50 \%$ in 2007 , is $9.1 \mathrm{~km}^{2}$ in size and has an elevation range between 1940 and $3630 \mathrm{~m}$ above sea level (asl). The hydrological regime of the study area is dominated by the presence of the glacier and the seasonal snow cover. The topography of the study site is characteristic for the complexity of mountainous terrain, with small flat surfaces having relatively high surface roughness (e.g. glacier forefield) alternated with steep and high side walls clearly confining the catchment (e.g. west ridge). In the forefield, a debris-covered dead-ice body with virtually no ice flow dynamics represents the most prominent feature. The catchment is the focus of a larger multidisciplinary project of the Competence Centre of Environment and Sustainability (CCES) at ETH Zurich with the aim of providing a detailed description of the processes occurring at the biosphere-hydrosphere-geosphere interface.

The topography of the study site is known from a high-accuracy digital elevation model (DEM) obtained from airborne photogrammetry in 2007. For the glaciercovered part of the catchment, two additional DEMs are available for 1939 and 1959 from digitized topographic maps. Glacier outlines for the three DEMs have been determined from the respective data source.

An automatic weather station (AWS) installed in the glacier forefield at $2025 \mathrm{~m}$ asl (Figure 1) recorded average air temperature and precipitation sums in $10 \mathrm{~min}$ intervals since October 2007. Additional temperature and precipitation data are available from the network of meteorological stations of the Federal Office of Meteorology and Climatology (MeteoSwiss).

Pictures of the study site were taken daily during the period between mid-May and the end of September 2008 with a conventional Olympus OM-2N photographic camera. The camera was located about $2 \mathrm{~km}$ from the catchment outlet and the field of view covered $62 \%$ of the catchment area (Figure 1). Pictures were taken automatically with a $28 \mathrm{~mm}$ unfiltered lens every day at 9 Am local time. The timing was chosen based on the incidence angle of the sunlight to get the best possible contrast in the region of interest. The camera was operated with Kodak Kodachrome ISO 64/19 $24 \times$ $36 \mathrm{~mm}$ films, which had to be replaced manually about once a month.

On 15 May 2008, just before the installation of the camera, a field survey was conducted to measure the SWE distribution in the catchment. A total of 227 snow depth measurements were collected, and one snow pit was dug for determining snow density (Figure 1).

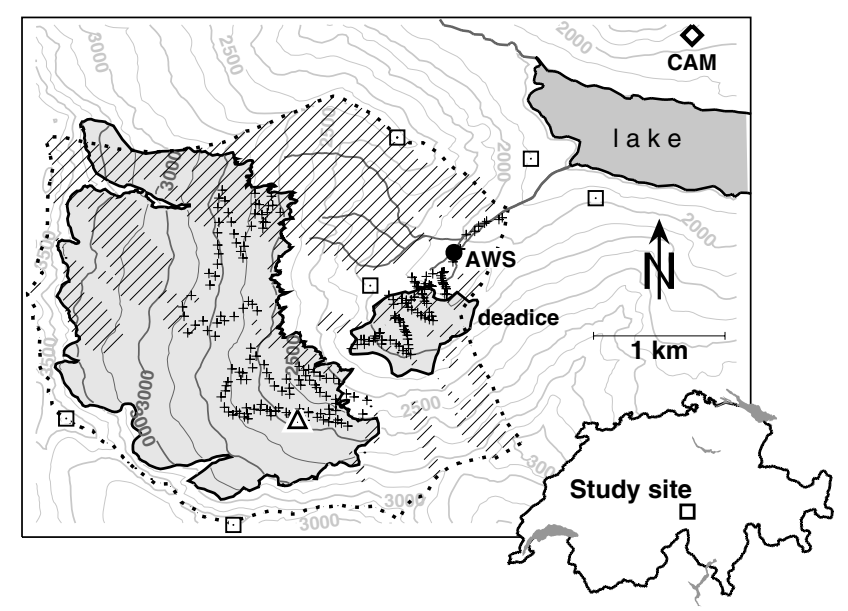

Figure 1. Study site overview. Terrain elevation is indicated by $100 \mathrm{~m}$ contour lines and the glacier is highlighted in light grey. The small glacier part at lower elevations is a dead-ice body. The positions of the automatic weather station (AWS) and the fixed camera (CAM) are shown. Regions of the catchment (dotted boundary) not seen from the camera are hatched. The locations of the snow depth measurements and the snow pit are shown by crosses and a triangle, respectively. Ground control points used for georeferencing are shown with a $\square$ symbol 
Density was determined by weighing snow samples collected with a metallic tube of known volume with a spring scale balance. Snow samples were taken in $50 \mathrm{~cm}$ depth intervals, and for each depth the procedure was repeated three times. The average density of the snowpack was then calculated as the arithmetic mean of all measurements.

\section{METHODS}

In order to get quantitative information from the sequence of pictures taken using the fixed camera, a georeferencing of the images was necessary. The snow cover evolution was then modelled combining a temperature index melt model and an accumulation model, both driven by daily temperature and precipitation time series. The accumulation model was adjusted to reproduce the shortterm evolution of the snow cover, that is, the melt-out pattern during a single season, whereas the melt model was adapted to match the glacier volume change observed during the period 1939-2007, reproducing, thus, the evolution on a longer time scale.

\section{Image processing}

For image processing, a method presented by Corripio (2004) was applied. The result is a snow cover map with the same resolution as the available DEMs, indicating for every grid cell whether the cell is snow-covered, snowfree or not visible from the position of the fixed camera. The image-processing procedure consists of five steps:

[1.] Selection of images: in the first step, images suitable for further processing were selected. The selection had the objective to provide a homogeneous chronosequence of the melt-out pattern, not biased by summer snowfall events. Images taken during cloudy or foggy days and images with clouds obscuring the view of the catchment were discarded. The images were chosen to obtain the best possible contrast for snow detection. This resulted in the selection of eight pictures, documenting the evolution of the melt-out during the period 23 May 2008 to 30 July 2008 in about 10-day intervals. Pictures taken after 30 July were discarded because of important snowfalls interrupting the melt-out pattern evolution.

[2.] Relative image adjustment: when operating conventional photocameras, small shifts in the camera orientation, for example, after the replacement of the film, are common. In order to correct these small variations in orientation, images chosen for further processing were adjusted relative to each other (Figure 2a). For this purpose, four reference points were manually selected in each of the eight pictures. The pictures were then rotated and deskewed to coregister the four points.

[3.] Detection of snow-covered area: while the detection of snow is relatively easy on bare soils or dark surfaces, at least during cloud-free days, the

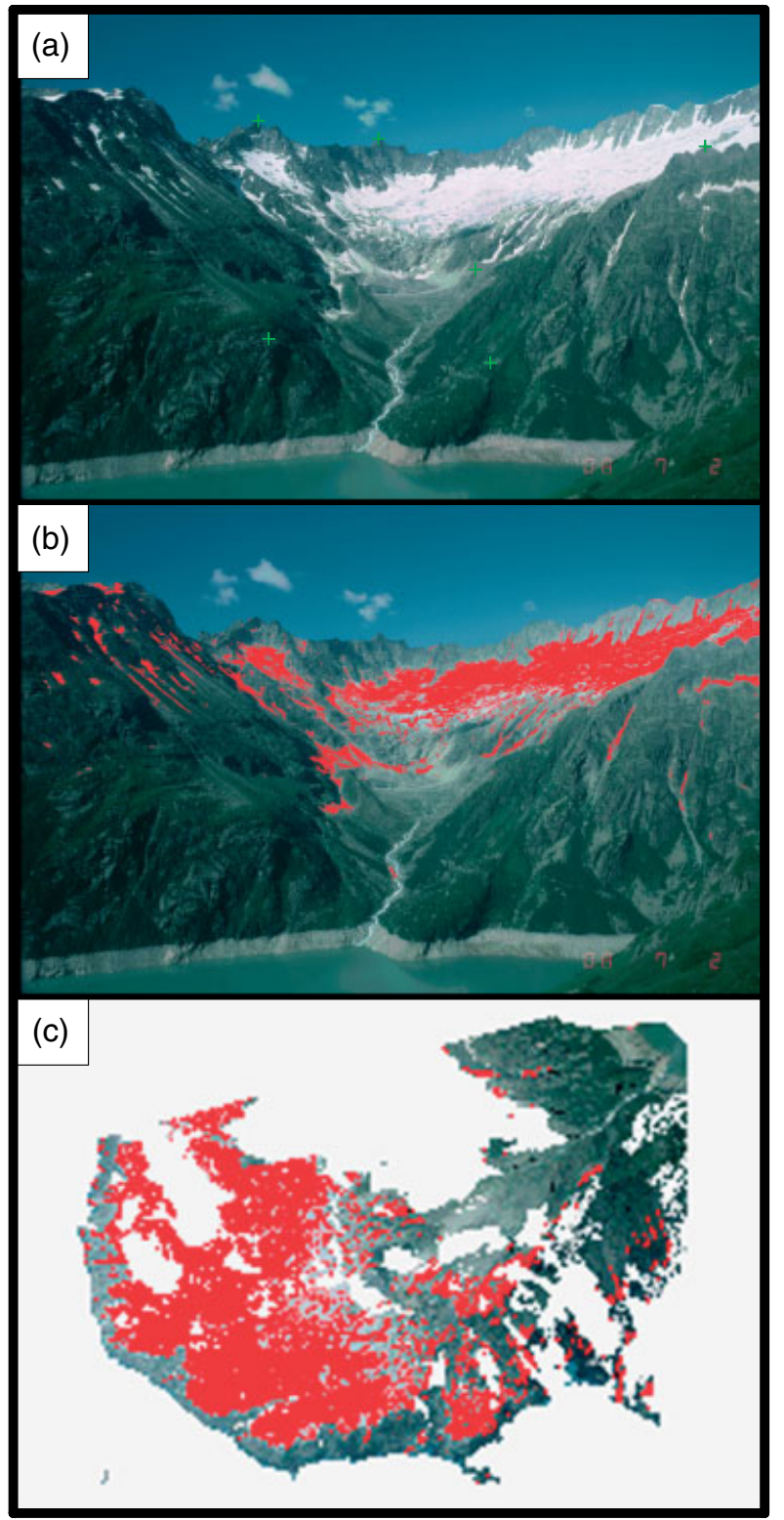

Figure 2. Steps of image processing. (a) Rotated and deskewed picture, ground control points are shown by crosses, (b) manually detected snow cover (red area), (c) georeferenced ortho-image of reflectance values (red: detected snow cover; green to grey: snow-free; white: invisible for the camera). The example refers to the image taken on 2 July 2008

distinction between snow and ice is more difficult in the visible band (e.g. Good and Martinec, 1987). Automatic snow detection procedures are, thus, generally unreliable. Because the camera used had no infrared sensor, the detection of snow-covered area was performed manually. This was performed by colouring zones interpreted as snow-covered using a commercial image-processing package (Figure $2 b$ ). The manual snow detection required approximately $30 \mathrm{~min}$ per processed image.

[4.] Georeferencing of images: the georeferencing of the images was performed using a procedure developed by Corripio (2004). Basically, the georeferencing procedure requires the definition of a function relating two-dimensional pixels in the photograph 
to three-dimensional points in the DEM. This is achieved by applying a perspective projection of the image pixels after transforming the coordinates of the DEM to the camera coordinate system. In this way, a 'virtual' photograph of the DEM is produced, that is, a two-dimensional representation of the relief information contained in the DEM, as seen from the point of view of the camera. By scaling this representation according to the resolution of the photograph, the necessary correspondence between pixels in the image, screen coordinates of the perspective projection of the DEM and their geographic location, can be established. The correct scaling functions are defined by matching the position of six ground control points (three manually installed ones and three well-defined mountain tops for which the position is known from topographic surveys, Figures 1 and 2a), to the corresponding locations on the images. The result is a georeferenced ortho-image of reflectance values. In case of visible photography, used in this study, reflectance refers to the three optical bands (red, green and blue) to which the film is sensitive (Figure 2c). The same method is, however, applicable to images representing other wavelengths as well (e.g. infrared photography). For further details on the georeferencing procedure refer to Corripio (2004).

[5.] Compilation of snow cover maps: the final step consists of the compilation of a series of gridded maps with same coordinates and resolution as the DEM, containing the information about the snow cover of each individual grid cell. This is achieved by detecting the previously marked snowcovered area through their reflectance value in the georeferenced images. Zones of the DEM which are not seen from the position of the camera are marked separately. The result is a series of eight maps, corresponding to the eight referenced photographs, in which every grid cell has one of the three possible values characterizing cells which are snow-covered, snow-free or not visible from the camera.

\section{Meteorological time series}

The measurements of the AWS installed in the catchment are not continuous in time due to brief malfunctions of the temperature sensor and to the unheated rain gauge, which does not allow measurement of solid precipitation. The meteorological time series had, thus, to be adjusted with measurements from surrounding stations of the MeteoSwiss network.

For air temperature, the station at Grimsel Hospiz (13 km from study site) shows an almost perfect linear relation with the measurements of the AWS for both hourly (correlation coefficient $r^{2}=0 \cdot 97$, average deviation $\overline{\Delta T}=0 \cdot 1{ }^{\circ} \mathrm{C}$, standard deviation $\sigma_{\Delta T}=1 \cdot 4^{\circ} \mathrm{C}$ ) and daily $\left(r^{2}=0 \cdot 99, \overline{\Delta T}=0 \cdot 1^{\circ} \mathrm{C}, \sigma_{\Delta T}=0 \cdot 8^{\circ} \mathrm{C}\right)$ values. The temperature data of this station were, thus, shifted by the observed average deviation and adopted, completely replacing the time series collected at the AWS.
For choosing a representative precipitation station to adjust the precipitation time series, daily precipitation sums recorded at the AWS were correlated with those at surrounding MeteoSwiss stations. Because no solid precipitation could be measured at the AWS, only days with a minimum hourly temperature greater than $3{ }^{\circ} \mathrm{C}$ were considered. The correlations were computed using daily and three-day aggregated values. Precipitation is generally known as a parameter which correlates poorly, even over short distances, in Alpine environments (e.g. Fliri, 1986; Frei and Schär, 1998). However, the correlation between the precipitation measured at the AWS and at the Göscheneralp station (3 km from the AWS, $280 \mathrm{~m}$ elevation difference) indicates that the approximation of the precipitation occurring in the catchment with that measured at the Göscheneralp station is reasonable. Daily aggregated values yield a correlation coefficient of $r^{2}=0.73\left(\overline{\Delta P}=0.3 \mathrm{~mm}, \sigma_{\Delta P}=5.4 \mathrm{~mm}\right)$ and threeday aggregated values of $r^{2}=0 \cdot 87(\overline{\Delta P}=1 \cdot 3 \mathrm{~mm}$, $\left.\sigma_{\Delta P}=5.5 \mathrm{~mm}\right)$. In this case, daily precipitation sums at the AWS $\left(P_{\text {AWS }}^{\prime}\right)$ were generated by linearly adjusting the precipitation records from Göschneralp $\left(P_{\mathrm{GOS}}\right)$ :

$$
P_{\mathrm{AWS}}^{\prime}=\left\{\begin{array}{ccc}
1 \cdot 31 \times P_{\mathrm{GOS}}+0 \cdot 81 & \text { if } & P_{\mathrm{GOS}}>0 \\
0 & \text { if } & P_{\mathrm{GOS}}=0
\end{array}\right.
$$

The relations between daily values of air temperature and precipitation measured at the AWS $\left(T_{\mathrm{AWS}}, P_{\mathrm{AWS}}\right)$ and the linearly transformed values of the chosen reference stations $\left(T_{\mathrm{AWS}}^{\prime}, P_{\mathrm{AWS}}^{\prime}\right)$ are shown in Figure 3.

\section{Melt modelling}

The modelling of the snow depletion was performed with a distributed temperature index model that accounts for potential direct clear sky solar radiation and neglects refreezing (Hock, 1999). This temperature index approach was chosen as it has been shown to be robust (e.g. Hock, 2005), is easy to implement and is driven by readily available meteorological data. The rate of daily snowmelt $M_{i}$ at a given location $i$ is computed according to:

$$
M_{i}=\left\{\begin{array}{ccc}
\left(f_{\mathrm{M}}+r_{\mathrm{snow}} \times I_{\mathrm{pot}, i}\right) \times \bar{T}_{i} & \text { if } & \bar{T}_{i}>0{ }^{\circ} \mathrm{C} \\
0 & \text { if } & \bar{T}_{i} \leq 0{ }^{\circ} \mathrm{C}
\end{array}\right.
$$

where $f_{\mathrm{M}}$ is a melt factor, $r_{\text {snow }}$ the radiation factor for snow, $I_{\mathrm{pot}, i}$ the potential direct clear sky solar radiation at the location $i$ and $\bar{T}_{i}$ the mean daily air temperature at the same location. The potential direct clear sky solar radiation is a function of the considered location and day of the year, accounting for effects of slope, aspect and shading, as well as for the seasonality in the incident solar radiation. Accounting for shading effects implies that the potential direct radiation is calculated at time steps shorter than one day. We used time steps of $1 \mathrm{~h}$ and computed daily values by integrating the results over 24 h. For further details refer to Hock (1999).

The mean daily air temperature at a given location is computed from the daily temperature at the AWS by means of a constant lapse rate. The lapse rate is 


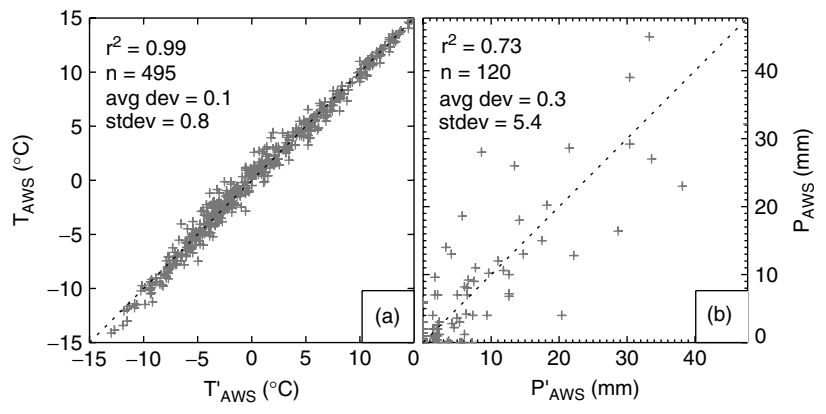

Figure 3. Relation between meteorological variables measured at the AWS $\left(T_{\text {AWS }}, P_{\text {AWS }}\right)$ and linearly transformed data of the reference stations chosen $\left(T_{\text {AWS }}^{\prime}, P_{\text {AWS }}^{\prime}\right)$. (a) Daily mean air temperature and (b) daily precipitation sum (days with minimum hourly temperature higher than $3{ }^{\circ} \mathrm{C}$ considered only). $r^{2}$ : squared correlation coefficient; $n$ : number of data points; avg dev: average deviation; stdev: standard deviation

determined from temperature records of 14 stations in the MeteoSwiss network ranging from elevations of 273 to $3580 \mathrm{~m}$ asl and is set to $-5 \cdot 6 \times 10^{-3}{ }^{\circ} \mathrm{C} \mathrm{m}^{-1}$.

The parameters in Equation 2 are adjusted to match the long-term glacier volume changes inferred from the available DEMs (Bauder et al., 2007), with an iterative calibration scheme proposed by Huss et al., (2008). We found $f_{\mathrm{M}}=1 \cdot 30 \times 10^{-3} \mathrm{~m}\left(\mathrm{~d}{ }^{\circ} \mathrm{C}\right)^{-1}$ and $r_{\text {snow }}=$ $1.36 \times 10^{-5} \mathrm{~m}^{3}\left(\mathrm{~W} \mathrm{~d}{ }^{\circ} \mathrm{C}\right)^{-1}$. Note that for the purpose of this study, only the parameters controlling snowmelt are of interest, although the used calibration procedure adjusts the parameters for icemelt as well.

\section{Accumulation modelling}

Precipitation is assumed to increase linearly with elevation with a lapse rate of $\mathrm{d} P / \mathrm{d} z$ (Peck and Brown, 1962). The gauge catch deficit is accounted for with a correction factor $c_{\text {prec }}$ (Bruce and Clark, 1981). A threshold temperature $T_{\text {thr }}$ distinguishes snow from rainfall, whereas the fraction of solid precipitation $r_{\mathrm{s}}$ linearly decreases from 1 to 0 in the temperature range $T_{\mathrm{thr}}-1{ }^{\circ} \mathrm{C}$ to $T_{\mathrm{thr}}+1{ }^{\circ} \mathrm{C}$ (Hock, 1999).

The spatial variation in accumulation of solid precipitation is influenced substantially by the preferential deposition and redistribution of snow (e.g. Lehning et al., 2008). Because most redistribution processes are controlled by topographic effects, snow distribution patterns are often consistent over time (e.g. Elder et al., 1991; Luce et al., 1998). A simple way to take advantage of this fact was presented by Jackson (1994) which accounted for the complex patterns of snow redistribution through a predefined spatial precipitation matrix. The matrix is applied to every event of solid precipitation in the form of a location-dependent 'snow multiplier' $D_{\text {snow }, i}$. The approach was applied successfully in some studies (e.g. Tarboton et al., 1995; Huss et al., 2009a).

Combining the described assumptions, the daily snow accumulation $C_{i}$ at any location $i$ with elevation $z_{i}$ during a day with measured precipitation $P_{\mathrm{AWS}}$ at the AWS is

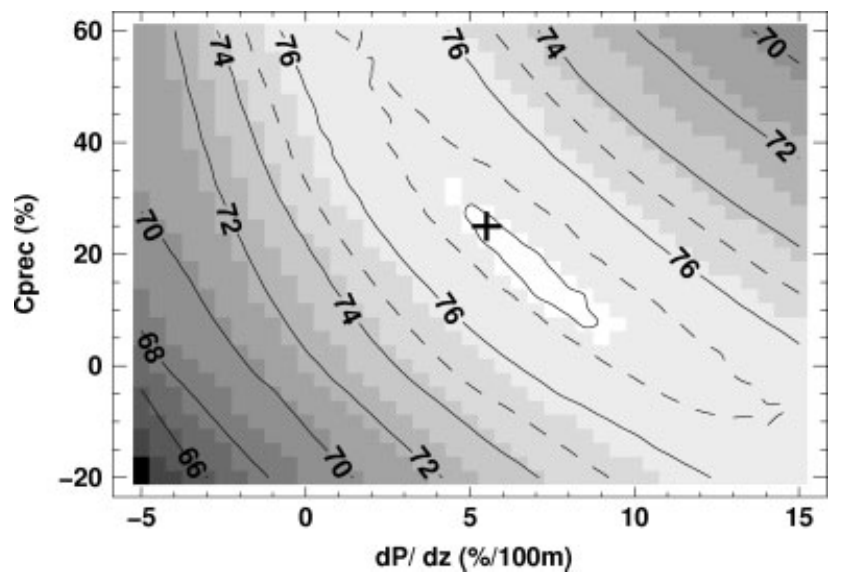

Figure 4. Calibration of the local precipitation gradient $\mathrm{d} P / \mathrm{d} z$ and the correction factor accounting for the gauge catch deficit $c_{\text {prec }}$. The grey scale and the contour lines indicate the goodness-of-fit measure, defined as the percentage of grid cells visible from the camera for which a correct snow cover was calculated. The best parameter combination (goodness-of-fit measure $=78.3 \%$ ) is marked by a cross

calculated as:

$$
\begin{aligned}
C_{i}= & P_{\mathrm{AWS}}^{\prime} \times\left(1+c_{\text {prec }}\right) \times\left[1+\left(z_{i}-z_{\mathrm{AWS}}\right)\right. \\
& \times \mathrm{d} P / \mathrm{d} z] \times D_{\text {snow }, i} \times r_{\mathrm{s}}
\end{aligned}
$$

\section{Calibration of the accumulation parameters}

The calibration of the parameters of the accumulation model is performed in a multilevel iterative procedure. First, $\mathrm{d} P / \mathrm{d} z$ and $c_{\text {prec }}$ are adjusted. This is performed by initializing the accumulation and melt model simultaneously at the end of August 2007 (a time of the year in which the catchment is assumed to be almost snow-free) and building up the snow cover during the 2007-2008 winter season. The simulated evolution of the melt-out pattern is then compared with the one observed during the melt season 2008. This procedure is repeated, systematically varying the parameters $\mathrm{d} P / \mathrm{d} z$ and $c_{\text {prec }}$. The fraction of area seen by the fixed camera for which a correct snow cover is simulated was defined as goodnessof-fit measure. This measure, which can be interpreted as the degree to which the observed melt-out pattern can be reproduced correctly, is computed by comparing the calculated and observed snow cover in every grid cell and averaging the percentage of correctly calculated grid cells over the eight snow cover maps available. As best estimate for the two parameters $\mathrm{d} P / \mathrm{d} z$ and $c_{\text {prec }}$, the combination which leads to the highest goodness-of-fit measure is chosen (Figure 4). We found $\mathrm{d} P / \mathrm{d} z=5.5 \% / 100 \mathrm{~m}$ and $c_{\text {prec }}=25 \%$.

In the second step, an analogous procedure is repeated systematically varying $T_{\mathrm{thr}}$. The concomitant variation of $\mathrm{d} P / \mathrm{d} z$ and $c_{\text {prec }}$ with the systematic variation of $T_{\text {thr }}$ showed that the best estimate for $T_{\text {thr }}$ is almost independent from the choice of the first two parameters. The best matching of calculated and observed snow cover evolution was found for $T_{\mathrm{thr}}=1.2^{\circ} \mathrm{C}$.

Finally, the snow multiplier matrix $D_{\text {snow }}$ is adjusted in the third step to optimize the spatial agreement 


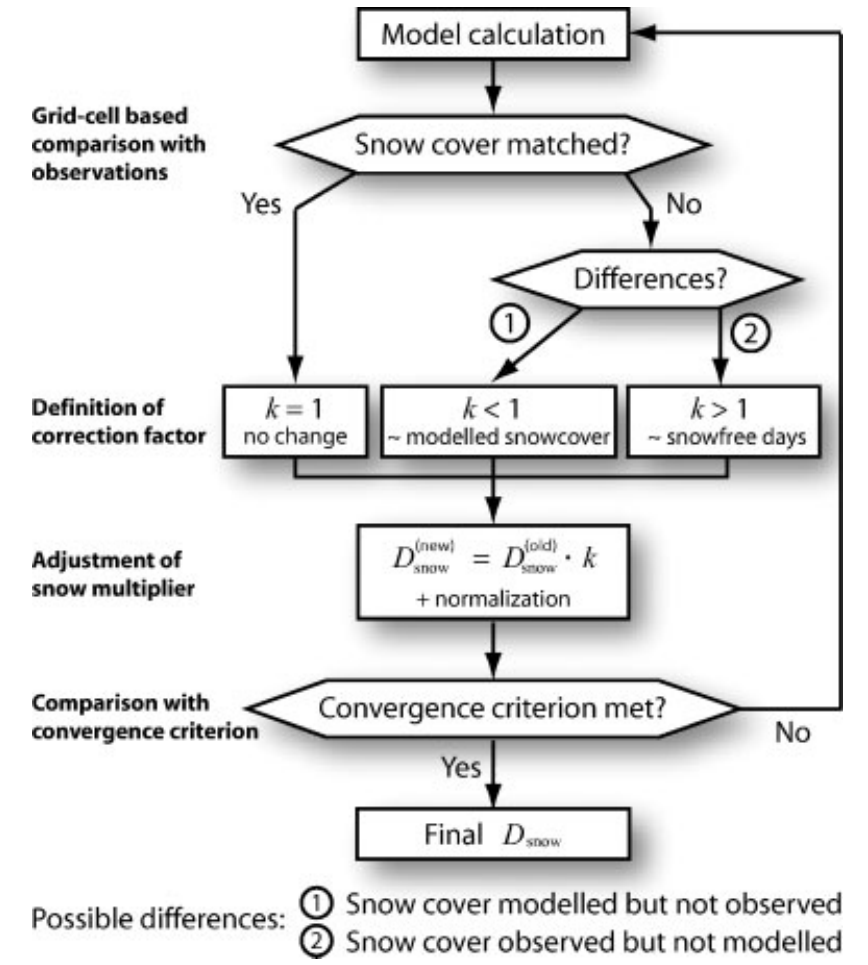

Figure 5. Calibration procedure used for adjusting the snow redistribution matrix $D_{\text {snow }}$

between simulated and observed melt-out pattern. This is performed iteratively, starting again the accumulation and melt modelling at the end of August 2007, and optimizing the previously defined goodness-of-fit measure for the melt-out patterns observed during the melt season 2008 (Figure 5). The unity matrix is chosen as the initial estimate for $D_{\text {snow }}$. At the end of each iteration loop, which consists of a one-year model run starting in August 2007, a location-dependent correction factor $k$ is applied to $D_{\text {snow. }} D_{\text {snow }}$ is assumed to be constant over the entire modelling period. The correction factor is calculated taking advantage of the information contained in grid cells for which a snow cover is simulated, but no snow cover is observed in the corresponding picture. In this case, the local value of $k$ is chosen to be inversely proportional to the SWE simulated for the given grid cell. For grid cells where snow cover is observed, but no snow cover is simulated, the definition of a correction factor is more complicated because no direct information about the magnitude of the misfit is available. However, the time interval between individual snow cover maps allows to estimate how long the situation 'no snow cover calculated, but observed' persists and thus gives a measure for the magnitude of the misfit. In this case, $k$ is chosen to be inversely proportional to the length of the persistence of the situation during the melting season. Note that because the eight pictures define seven time intervals in which the situation 'no snow cover calculated, but observed' can occur (or not occur) independently, $k$ assumes one of the $\sum_{i=1}^{7} 2^{i}=254$ possible discrete values. For grid cells where the snow cover is simulated correctly, or the fixed camera has no insight, the local

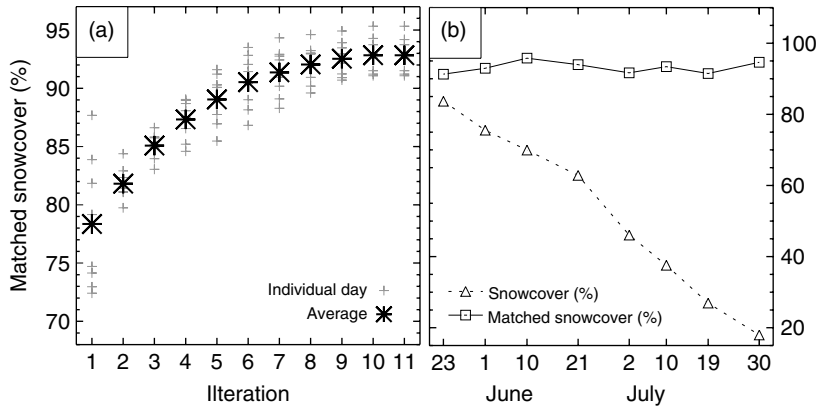

Figure 6. Evolution of the goodness-of-fit measure (percentage of snow-covered grid cells reproduced correctly) for the optimization procedure. (a) Convergence is reached after about ten iterations. (b) The goodness-of-fit measure is almost constant over the melt-out period and is independent from the snow coverage observed in the catchment. Percentages are normalized over the portion of the catchment seen by the camera. Days of the year 2008 for which a snow cover map is available are shown on the time axis

value of $k$ is set to 1 . The adjustment of $D_{\text {snow }}$ is performed in each iteration loop after the simulation of the last day with a snow cover map by multiplying $D_{\text {snow }}$ with $k$. In order to cause $D_{\text {snow }}$ to redistribute the solid precipitation without affecting the total amount, the matrix is normalized over the catchment domain to an average value of 1 . After the adjustment of $D_{\text {snow, }}$ the melt and accumulation models are restarted, and the whole procedure repeated until convergence. The change in the goodness-of-fit measure compared with the value of the previous iteration loop is defined as convergence criterion. The iteration is aborted for a change less than $0.1 \%$.

Note that at this stage, it is impossible to discern whether the calibrated accumulation parameters are correct or biased to compensate errors arising form the melt calculation. This problem will be discussed and solved later in the text (see Sections Validation and Sources of Uncertainty).

\section{RESULTS AND DISCUSSION}

\section{Resulting snow accumulation distribution}

The procedure for the adjustment of the snow multiplier matrix converges after about ten iterations (Figure 6a). On average over the eight available snow cover maps, the snow cover can be reproduced correctly for about $93 \%$ of the grid cells seen by the fixed camera (Figure 6b). The high level of correctly calculated grid cells is almost constant over the melt-out season and independent from the degree to which the catchment is snow-covered (Figure 6b).

The resulting snow accumulation distribution for a hypothetical day with $10 \mathrm{~mm}$ precipitation measured at the AWS and solid precipitation occurring in the entire catchment is shown in Figure 7. The effect of steep slopes is evident. On the upper ridges of the basin, as well as on the north-facing steep slopes and the lateral moraines of the forefield, snow accumulation is very limited. However, large snow deposits are recognizable in the 


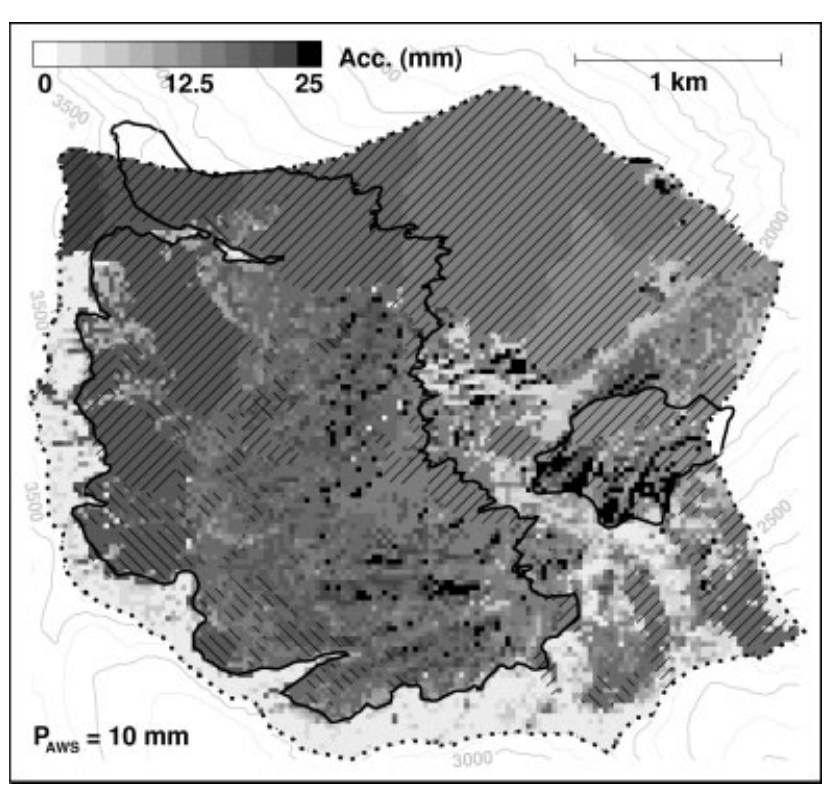

Figure 7. Snow accumulation distribution inferred for a hypothetical day with $10 \mathrm{~mm}$ precipitation at the AWS and no liquid precipitation occurring in the catchment. In zones not seen by the fixed camera (hatched///) and in zones with permanent snow cover (hatched $\backslash \backslash \backslash$ ), $D_{\text {snow }}$ cannot be adjusted

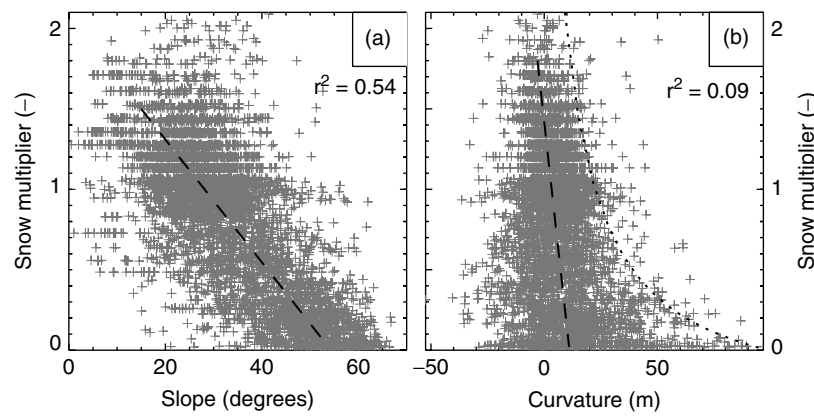

Figure 8. Correlation of the snow multiplier $D_{\text {snow }}$ with (a) local slope, and (b) local terrain curvature. Dashed lines are fitted by linear regression. The dotted line in (b) indicates a threshold curvature for the maximal predicted value of $D_{\text {snow }}$. Slope is evaluated on a $25 \mathrm{~m}$ grid, curvature with a radius of $125 \mathrm{~m}$

southern sector of the dead-ice body. These deposits were observed indeed during the field survey and were mainly caused by avalanches. Note that in zones not seen by the camera and in zones which are snow-covered throughout the melting season, the accumulation distribution remains a function of elevation only because no information is available for adjusting $D_{\text {snow }}$ (Figure 7, hatched area).

Because processes affecting the snow accumulation distribution are often controlled by topography (e.g. Elder et al., 1991), the values inferred for the snow multiplier matrix $D_{\text {snow }}$ are correlated with two topographic variables: local slope (Figure 8a) and curvature (Figure 8b). The correlations were evaluated only for zones for which $D_{\text {snow }}$ could be adjusted (non-hatched area in Figure 7).

Curvature is a topographic attribute used as proxy for the degree of wind exposure of a given grid cell and has often been used for explaining some variance in the observed distribution of snow accumulation due to wind drift (e.g. Elder et al., 1989; Blöschl et al., 1991;
Huss et al., 2008; Carturan et al., 2009). We compute the parameter as the difference between the local altitude and the average altitude of a portion of terrain lying inside a given radius (Carturan et al., 2009). According to this definition, negative curvature values indicate concave terrain (hollows) and positive values convex terrain (hills).

In spite of the large scatter, values inferred for $D_{\text {snow }}$ show a significant correlation with local slope $\left(r^{2}=0.54\right.$, Figure 8a). This is attributable to gravity-driven mechanisms of snow redistribution as avalanching and slushflow, as well as wind drift and wind erosion processes taking place on steep walls because of downward winds. The linear relation fitted to the data indicates that the terrain is almost permanently snow-free for local slopes exceeding about $55^{\circ}$. This is in agreement with results of earlier studies (e.g. Witmer, 1984; Blöschl and Kirnbauer, 1992). On the basis of intercomparison of different studies, Blöschl et al., (1991) pointed out that the local slope for which hillsides become permanently snow-free may depend on the cell size of the underlying grid. In order to analyse this effect, we re-evaluated the correlation between inferred values of $D_{\text {snow }}$ and local slope resampling the DEM to 50,75 and $100 \mathrm{~m}$ resolution. When increasing cell size we observed a decrease in the correlation coefficient $\left(r^{2}=0.54\right.$ for $25 \mathrm{~m}$ and $r^{2}=0.44$ for $100 \mathrm{~m}$ cell size) as well as a decrease in the local slope for which hillsides become permanently snow-free $\left(55^{\circ}\right.$ for $25 \mathrm{~m}$ and $45^{\circ}$ for $100 \mathrm{~m}$ ). This is attributed to the smoother topography caused by larger grid cells, resulting in reduced local slope.

The linear correlation between $D_{\text {snow }}$ and curvature is weak $\left(r^{2}=0.09\right.$, Figure $\left.8 b\right)$. This can, however, not be interpreted as the absence of influence of curvature on $D_{\text {snow. }}$. The effect may be masked by interactions with other factors or not be linear. In fact, curvature controls the maximal value inferred for $D_{\text {snow }}$. Very low values of $D_{\text {snow }}$ are found over almost the whole range of curvature values, whereas very high values of $D_{\text {snow }}$ occur only at curvatures close to zero (dashed line in Figure 8b). This means that zones where snow accumulation is significantly below average occur independently of the concavity of the terrain, whereas zones with high aboveaverage snow accumulation are only present in rather flat areas (neither concave nor convex terrain). The sensitivity of the definition of curvature was assessed varying the evaluation radius in the range of 50 to $200 \mathrm{~m}$. The effect on the relation between curvature and $D_{\text {snow }}$ is small. The correlation coefficient becomes somewhat larger towards a smaller radius $\left(r^{2}=0.20\right.$ for $50 \mathrm{~m}$ radius and $r^{2}=0.08$ for $200 \mathrm{~m}$ radius), but the limiting effect of curvature remains visible.

The linear correlation of $D_{\text {snow }}$ with some other topographically controlled parameters was explored without detecting significance or simple interpretable patterns. In particular, this was the case for aspect and potential solar radiation. However, similarly as stated for curvature, the absence of significant correlations cannot be interpreted as the absence of influence of the analysed factors on 
$D_{\text {snow }}$ as effects may be masked by interactions with other parameters.

\section{Validation}

In order to validate the inferred snow accumulation distribution, the model was re-initialized at the end of August 2007, building up the snow cover during the 2007-2008 winter season. Thereby, all solid precipitation events are redistributed according to $D_{\text {snow }}$. According to the modelling, the field survey providing the direct SWE measurements was conducted two weeks after the maximal SWE was reached in the catchment (Figure 9).

Considering a one-year period starting from the end of August 2007, $87 \%$ of the accumulation and $16 \%$ of the melt occurred before the field survey. The collected SWE measurements are thus suitable for a validation of the inferred snow accumulation distribution and the accumulation model, as they are not biased significantly by melt processes. The calculated and measured SWE distribution for 15 May 2008 agrees well in the point-topoint comparison (Figure 10a). The difference between observed and calculated average snow depth $\overline{\Delta h}$ is $5 \mathrm{~cm}$ water equivalent (w.e.), with a standard deviation of the residuals $\sigma_{\Delta h}$ of $28 \mathrm{~cm}$ w.e. The inferred snow accumulation distribution explains $51 \%$ of the observed variance in the sample of measured snow depths.

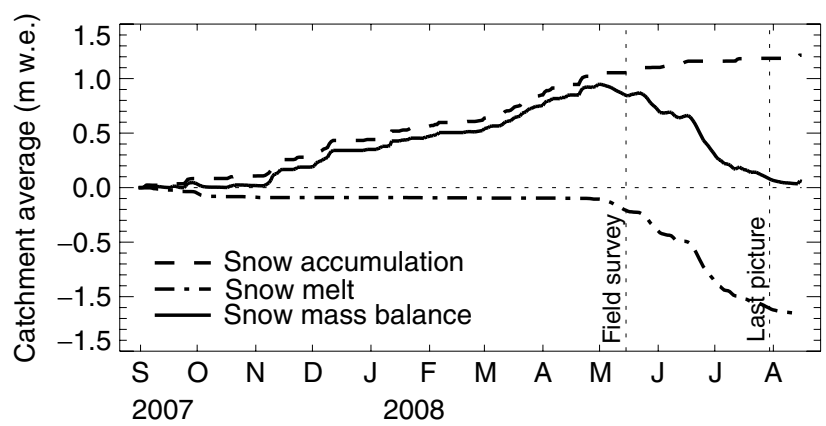

Figure 9. Temporal evolution of the mass balance of the snowpack. A time span of one year is shown. The day of the field survey and the day for which the last snow cover map is available are marked. The mass balance components are averaged over the catchment area seen by the fixed camera

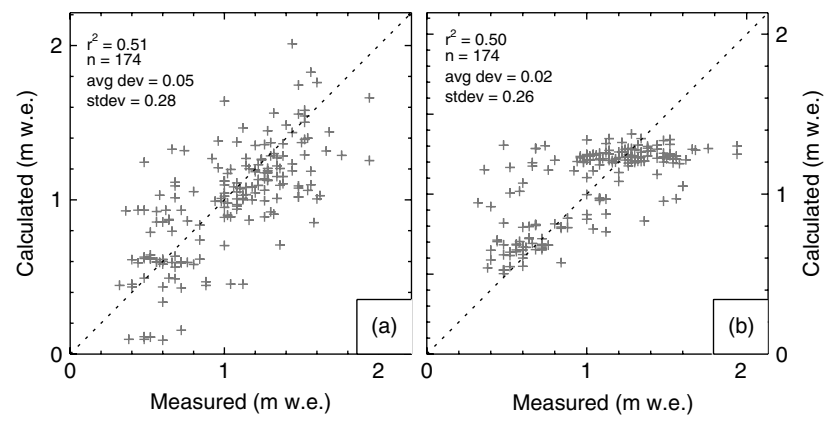

Figure 10. Comparison between snow depths measured on 15 May 2008 and calculated snow depth using (a) the inferred accumulation distribution, and (b) an inverse distance interpolation procedure applied $N$ times, omitting one data point at each time. For comparison, only measurements in regions seen by the fixed camera were considered (Figure 1)
In order to compare the accuracy of the resulting snow distribution with other possible methods for estimating the SWE distribution, two additional experiments were conducted.

1. In the first experiment, the SWE distribution for the day of the field survey was calculated building up the snow cover during the 2007-2008 winter season using the same accumulation and melt model as described above but setting the snow multiplier matrix $D_{\text {snow }}$ uniformly to 1 . The residuals between calculated and measured snow depths at the locations of direct measurement were then used as estimator for the accuracy of the experiment. The standard deviation of the residuals was $\sigma_{\Delta h}=31 \mathrm{~cm}$ w.e. and is, thus, not significantly larger than $\sigma_{\Delta h}$ calculated when $D_{\text {snow }}$ is adjusted as previously described. This relatively small standard deviation can be explained with the correlation of the measured snow depth with altitude $\left(r^{2}=0.42\right)$ and the fact that setting the snow multiplier matrix to 1 causes the precipitation to become a function of altitude only (Equation 3). The difference between mean measured and mean calculated SWE is, however, high $(\overline{\Delta h}=-33 \mathrm{~cm}$ w.e.). This offset could be corrected by adjusting the factor $c_{\text {prec }}$, but this would cause the degree to which the observed melt-out pattern can be reproduced to decrease from about $93 \%$ (Figure 6) to about $77 \%$ (Figure 4).

2. In the second experiment, the SWE distribution for the day of the field survey was obtained by inverse distance weighting of the direct measurements. In this case, the uncertainty was assessed by starting the inverse distance interpolation $N$ times, omitting one measurement point each time. The residuals were then computed, storing the deviation between measured and calculated SWE at the omitted measurement point in each step ('cross validation'). The standard deviation of the residuals of this experiment is $\sigma_{\Delta h}=26 \mathrm{~cm}$ w.e., whereas the average snow depth is matched exactly $(\overline{\Delta h}=0 \mathrm{~cm}$ w.e. $)$. The explained variance is $50 \%$ (Figure 10b). In respect to the variance of the residuals, no significant difference is observed between the results of this second experiment and the SWE distribution inferred through the adjustment of $D_{\text {snow. }}$. The result is astonishing, because the inverse distance weighting procedure is based exclusively on the snow depth measurements, whereas the inferred accumulation distribution for solid precipitation relies on the observed melt-out pattern only. Of course, the variance of the residuals of the inverse distance weighting interpolation is expected to decrease with increasing number of snow depth measurements and with a more homogeneous distribution of the measurement points. This, however, is a result which is difficult to achieve, because the required effort in terms of field work is large. 
A comparison of the two described experiments shows that (1) the adjustment of $D_{\text {snow }}$ with the presented procedure enhances significantly the degree to which the measured SWE distribution can be reproduced, and (2) the inferred SWE distribution is comparable in terms of standard deviation of the residuals with the result achieved by interpolating direct snow depth measurements with a inverse distance interpolation scheme.

Once the accumulation model has been proven to be sufficiently accurate, the performance of the combined model (accumulation and melt) during the ablation season can be interpreted as well.

According to Figure 9, only $12 \%$ of the accumulation but as much as $78 \%$ of the melt of a one-year period starting from the end of August 2008 occurs between the day of the field survey (15 May 2008) and the last available snow cover map (30 July 2008). The matching of the modelled melt-out pattern evolution with the observed one in this period thus indicates that the melt model performs well and that the melt parameters calibrated using the long-term ice volume changes are in a reasonable range.

\section{Sources of uncertainty}

Different sources of uncertainty affect the accuracy of the inferred parameters for the accumulation model; estimating their magnitude is, however, difficult.

The accuracy of the image-referencing procedure was assessed by picking one prominent feature on all available images, for which the position was determined from the aerial photograph used for the preparation of the DEM. The feature was chosen as far as possible from the position of the fixed camera, where the resolution of the image in terms of image pixels per real meter length is minimal (about 0.41 pixel per meter), and in a location where the incidence angle of the camera was estimated to be representative for the whole picture. The images on which the feature was picked were then georeferenced and the transformed position of the feature was compared with the previously determined coordinates. In all cases, the transformed position matched the known coordinates within twice the resolution of the DEM, that is, $50 \mathrm{~m}$. We assume this value to be representative for the average accuracy of the georeferencing procedure, although for flat zones, where the incidence angle of the camera becomes small, the accuracy may be lower.

The accuracy of the compiled snow cover maps is also determined by the accuracy with which snow-covered area of the picture can be detected. Quantifying this accuracy is difficult, as it is both location- and timedependent. Snow detection is relatively easy in the early season, when almost the whole catchment is snowcovered and the area becoming snow-free is concentrated in the low-lying glacier forefield (where the contrast to the bare ground is high) and on steep mountain ridges (where the incidence angle of the camera is high). However, detection becomes difficult later in the season, when the snowline retreats to the glacierized parts of the basin, where the contrast between snow and underground (i.e. bare ice) is less pronounced. On the basis of the experiences collected during the manual detection of the snow cover on the images, we estimate the accuracy to be in the order of 50-75 $\mathrm{m}$ in the glacierized parts of the catchment and in the order of the DEM resolution (i.e. $25 \mathrm{~m}$ ) in the remaining area.

Several uncertainty sources are introduced due to assumptions made for accumulation and melt modelling. The daily precipitation sums driving the accumulation model are not measured in situ but taken from a station outside the catchment. The threshold temperature distinguishing solid and liquid precipitation is assumed to be constant, although Rohrer (1989) reported a tendency towards lower threshold temperatures in summer than in winter, and constant lapse rates are assumed for precipitation and temperature too. The threshold temperature is based on daily mean temperature, excluding thus smaller snowfall events, for example, during cold nights, and the snow multiplier matrix, redistributing the solid precipitation instantaneously, is assumed to be constant over time. Finally, the parameters of the melt model are calibrated with long-term ice volume changes and assumed to be constant over time as well, although a significant yearto-year variation was pointed out by Huss et al., (2009b). Assessing the effect of each assumption on the overall accuracy is difficult, as no direct measurements are available for validation. Moreover, uncertainties induced by different assumptions can potentially compensate for one another. The inferred snow multiplier matrix could, thus, also be regarded as a parameter lumping corrections for uncertainties arising from different model assumptions, although being mainly determined by processes controlling the redistribution of snow accumulation. However, the timing of the field survey and the beginning of the snow cover monitoring divide two distinct periods dominated either by accumulation or by melt. This allows us to state that both model components-representing accumulation and melt-reproduce the observations reasonably and independently from each other.

The direct measurements of snow depth used for validation are affected by uncertainties as well. Although the accuracy in individual snow depth measurements is high (accuracy of reading $= \pm 5 \mathrm{~cm}$ ), uncertainty is introduced by the roughness of the underground, which may cause individual measurements not to be representative for larger areas. On glaciers, the ice surface is generally smoother than the surface of bare soils, thus making individual measurements representative for larger portions of terrain, but the detection of the correct sounding horizon is not always easy, especially for measurements in the firn area. Moreover, a homogeneous distribution of the collected measurement (Figure 1) was hampered by the avalanche risk in the catchment. This resulted in a dataset which is slightly biased towards relatively small surface slopes.

Further uncertainty is introduced by the conversion of measured snow depth into SWE. Also in this case, the snow density measured at a single location may not be 
representative for the whole area. This uncertainty source has potential for systematic errors when assessing the total SWE of the catchment. The modelling procedure has the advantage of computing SWE directly, without requiring further information on snow density.

\section{Potential, recommendations and limitations for further applications}

The method as presented relies on images taken through terrestrial oblique photography in the visible band (VIS) and was developed in an Alpine environment. However, it can easily be applied using any kind of sensor able to observe melt-out pattern evolution (e.g. aerial photography or satellite imagery) and is not restricted to glacierized or mountainous catchments. We see a large potential for application to remote and inaccessible areas, where the seasonal depletion of the snow cover has significant impacts on hydrology or other processes (e.g. Siberia, Himalaya, Canadian plains).

For a faster and more accurate snow detection in the images, we recommend the use of imagery sensible to both, VIS and near infrared (NIR), as combination of this information has been shown to be suitable for automatic snow detection (e.g. Hall et al., 1995). The accuracy of the snow detection also depends on the incidence angle of the fixed camera. The position of the camera should, thus, be chosen so that the incidence angle is as close as possible to $90^{\circ}$. We furthermore recommend the use of a digital camera, which reduces the effort required for operating the camera and simplifies some steps of the image processing. When working on VIS, attention has to be paid to the time of the day at which images are taken because shadows or reflections may compromise the possibility of detecting snow visually.

We calibrate the parameters of the melt model to long-term ice volume changes. This is, however, not the only possible procedure. Empirical temperature index snowmelt parameters for different areas may be, for example, calibrated with snow depth data collected at stakes or by a sonic ranger and in combination with local temperature and precipitation measurements.

The monitoring of the melt-out pattern should start the latest at the beginning of the melting season. This is crucial for allowing the melt and the accumulation model to be validated separately.

According to our experience, snow cover maps compiled at intervals of 10-20 days are suitable for the application of the method. However, the interval at which individual pictures are taken should be considerably smaller (e.g. one to three days) as, especially when operating in VIS, several pictures may not be suited for further processing because of reduced visibility due to fog or clouds. Local meteorological conditions may thus limit the applicability of the method to some regions.

The calibration scheme for $D_{\text {snow }}$ (Figure 5) limits the application to areas where the seasonal snow cover melts completely, or at least to regions where snow layers from different seasons are clearly recognizable. This, for instance, is often not the case in accumulation zones of glaciers.

\section{CONCLUSIONS}

The evolution of the melt-out pattern observed during one ablation season using conventional oblique photography was combined with a temperature index melt model and a simple accumulation model to infer the snow accumulation distribution of a small Alpine catchment. On average over the melt-out season, the observed snow cover depletion could be reproduced correctly in $93 \%$ of the area seen by the fixed camera. The inferred snow accumulation distribution was validated with in situ snow depth measurements. The comparison with the results of an inverse distance interpolation of direct measurements showed that the inferred accumulation distribution is able to explain almost the same fraction of variance in the snow depth measurements. Correlations with topographic variables showed a large scatter, but a significant linear relation with local slope was found. Curvature was detected as a factor controlling the maximal local accumulation. Quantifying an overall accuracy is difficult as there are various sources of uncertainty which may compensate for one another to some degree.

Our results suggest that the method is suitable for inferring the spatial distribution of SWE in remote areas without the need of direct access for field measurements, as long as melt-out patterns are observable. As the distribution of snow in mountain regions is highly complex and difficult to reproduce with unconstrained modelling, the presented method has the potential to enhance the performance of models in different fields. Better representation of SWE and its spatial variability is of crucial importance for distributed hydrological models providing runoff forecasts, the monitoring of glacier mass balance or avalanche forecasting.

\section{ACKNOWLEDGEMENTS}

Financial support for this study was provided by the BigLink project of the Competence Center Environment and Sustainability (CCES) of the ETH Domain. Swisstopo provided topographic maps and aerial photographs. H. Bösch evaluated the DEMs from aerial photographs. Many thanks to J. Corripio, who provided substantial support in the georeferencing of the images. M. Lehning made valuable comments on earlier versions of the manuscript. S. Braun-Clarke edited the English. We acknowledge M. Anderson for the editorial work and R. Dadic and two anonymous reviews for their helpful remarks.

\section{REFERENCES}

Basist A, Bell GD, Meetemeyer V. 1994. Statistical relationships between topography and precipitation patterns. Journal of Climate 7: $1305-1315$. 
Bauder A, Funk M, Huss M. 2007. Ice volume changes of selected glaciers in the Swiss Alps since the end of the 19th century. Annals of Glaciology 46: 145-149.

Blöschl G, Kirnbauer R. 1992. An analysis of snow cover patterns in a small alpine catchment. Hydrological Processes 6: 99-109.

Blöschl G, Kirnbauer R, Gutknecht D. 1991. Distributed snowmelt simulations in an Alpine catchment, I: model evaluation on the basis of snow cover patterns. Water Resources Research 12(27): 3171-3179.

Bruce JP, Clark RH. 1981. Introduction to Hydrometeorology. Pergamon Press: Oxford.

Carturan L, Cazorzi F, Dalla Fontana G. 2009. Enhanced estimation of glacier mass balance in unsampled areas by means of topographic data. Annals of Glaciology 50(50): 37-46.

Corripio JG. 2004. Snow surface albedo estimation using terrestrial photography. International Journal of Remote Sensing 25(24): 5705-5729.

Dadic R, Mott R, Lehning M, Burlando P. 2010. Wind influence on snow depth distribution and accumulation over glaciers. Journal of Geophysical Research, in press, DOI:10.1029/2009JF001261.

Davis RE, McKenzie JC, Jordan R. 1995. Distributed snow process modelling: an image processing approach. Hydrological Processes 9: $865-875$.

Doorschot J, Raderschall N, Lehning M. 2001. Measurements and onedimensional model calculations of snow transport over a mountain ridge. Annals of Glaciology 32: 153-158.

Dozier J, Painter TH. 2004. Multispectral and hyperspectral remote sensing of alpine snow properties. Annual Review of Earth and Planetary Sciences 32: 465-494.

Egli L. 2008. Spatial variability of new snow amounts derived from a dense network of Alpine automatic stations. Annals of Glaciology 49: $51-55$.

Elder K, Dozier J, Michaelsen J. 1989. Spatial and temporal variation of net snow accumulation in a small alpine watershed, Emerald Lake basin, Sierra Nevada, California,U.S.A. Annals of Glaciology 13: 56-63.

Elder K, Dozier J, Michaelsen J. 1991. Snow accumulation and distribution in an alpine watershed. Water Resources Research 27: $1541-1552$.

Essery R, Martin E, Douville H, Fernańdez A, Brun E. 1999. A comparison of four snow models using observations from an alpine site. Climate Dynamics 15: 583-593.

Fliri F. 1986. Synoptisch-klimatologische Niederschlagsanalyse zwischen Genfersee und Hohen Tauern. Wetter Leben 38: 140-149.

Frei C, Schär C. 1998. A precipitation climatology of the Alps from high-resolution rain-gauge observations. International Journal of Climatology 18(8): 873-900.

Good W, Martinec J. 1987. Pattern recognition of air photographs for estimation of snow reserves. Annals of Glaciology 9: 76-80.

Hall DK, Riggs GA, Salomonson VV. 1995. Development of methods for mapping global snow cover using moderate resolution imaging spectroradiometer data. Remote Sensing of Environment 54: 127-140.

Hock R. 1999. A distributed temperature-index ice- and snowmelt model including potential direct solar radiation. Journal of Glaciology 45(149): $101-111$.

Hock R. 2005. Glacier melt: a review of processes and their modelling. Progress in Physical Geography 29(3): 362-391.

Huss M, Bauder A, Funk M, Hock R. 2008. Determination of the seasonal mass balance of four Alpine glaciers since 1865. Journal of Geophysical Research 113: F01015.

Huss M, Bauder A, Funk M. 2009a. Homogenization of long-term mass balance time series. Annals of Glaciology 50(50): 198-206.

Huss M, Funk M, Ohmura A. 2009b. Strong Alpine glacier melt in the 1940s due to enhanced solar radiation. Geophysical Research Letters 36: L23501.

Jackson THR. 1994. A spatially distributed snowmelt-driven hydrologic model applied to Upper Sheep Creek. PhD thesis, Utah State University, Logan, Utah.

Kind RJ. 1981. Snow drifting. In Handbook of Snow: Principles, Processes, Management and Use, Gray DM, Male DH (eds). Elsevier: New York; 338-359.

König M, Winther J-G, Isaksson E. 2001. Measuring snow and glacier ice properties from satellite. Reviews of Geophysics 39(1): 1-27.

Leavesley GH, Stannard LG. 1990. Application of remotely sensed data in distributed-parameter watershed model. Proceedings of the workshop on applications of remote sensing in hydrology, Kite GW, Wankiewicz A (eds), National Hydrology Research Institute: Saskatoon, Saskatchewan, CA; 47-64.

Lehning M, Loewe H, Ryser M, Raderschall N. 2008. Inhomogeneous precipitation distribution and snow transport in steep terrain. Water Resources Research 44(7): W07404.

Lehning M, Völksch I, Gustafsson D, Nguyen TA, Staehli M, Zappa M. 2006. ALPINE3D: a detailed model of mountain surface processes and its application to snow hydrology. Hydrological Processes 20: 2111-2128.

Liston GE, Sturm M. 1998. A snow-transport model for complex terrain Journal of Glaciology 44(148): 498-516.

Luce CH, Tarboton DG, Cooley KR. 1998. The influence of the spatial distribution of snow on basin-averaged snowmelt. Hydrological Processes 12: 1671-1683.

Luckman BH. 1977. The geomorphic activity of snow avalanches. Geografiska Annaler 59(1/2): 31-48.

Machguth H, Eisen O, Paul F, Hoelzle M. 2006. Strong spatial variability of snow accumulation observed with helicopter-borne GPR on two adjacent Alpine glaciers. Geophysical Research Letters 33: L13503.

Martinec J, Rango A. 1981. Areal distribution of snow water equivalent evaluated by snow cover monitoring. Water Resources Research 17(5): 1480-1488.

Mesinger F, Pierrehumbert RT. 1986. Alpine Lee Cyclogenesis: Numerical Simulation and Theory, Scientific Results of the Alpine Experiment (ALPEX), GARP Publication Series, vol. I(27), World Meteorological Organization (WMO); 141-163.

Mittaz C, Imhof M, Hoelzle M, Haeberli W. 2002. Snowmelt evolution mapping using an energy balance approach over an alpine terrain. Arctic Antarctic and Alpine Research 34(3): 274-281.

Nemoto M, Nishimura K. 2004. Numerical simulation of snow saltation and suspension in a turbulent boundary layer. Journal of Geophysical Research 109: D18206.

Peck EL, Brown MJ. 1962. An approach to the development of isohyetal maps for mountainous areas. Journal of Geophysical Research 67: 681-694.

Rohrer M. 1989. Determination of the Transition Air Temperature from Snow to Rain and Intensity of Precipitation, Sveruk B (ed.). Precipitation measurement, ETH Zurich: Switzerland; 475-482.

Schaefli B, Hingray B, Niggli M, Musy A. 2005. A conceptual glaciohydrological model for high mountainous catchments. Hydrology and Earth System Sciences 9: 95-109.

Schmidt RA. 1986. Transport rate of drifting snow and the mean wind speed profile. Boundary-Layer Meteorology 34: 213-241.

Seyfried MS, Wilcox BP. 1995. Scale and the nature of spatial variability: field examples having implications for hydrologic modeling. Water Resources Research 31: 173-184.

Shi J, Dozier J. 2000a. Estimation of snow water equivalence using SIR-C/X-SAR, Part I: inferring snow density and subsurface properties. IEEE Transactions on Geoscience and Remote Sensing 38(6): 2465-2474.

Shi J, Dozier J. 2000b. Estimation of snow water equivalence using SIR-C/X-SAR, Part II: inferring snow depth and particle size. IEEE Transactions on Geoscience and Remote Sensing 38(6): 2475-2488.

Spreen WC. 1947. A determination of the effect of topography upon precipitation. Transactions-American Geophysical Union 2: 285-290.

Tarboton DG, Chowdhury TG, Jackson TH. 1995. A spatially distributed energy balance snowmelt model. In Biogeochemistry of Seasonally Snow-covered Catchments, Proceedings of a Boulder Symposium, Tonnessen KA, Williams MW, Tranter M (eds) IAHS Publ. no. 228. IAHS Publication: Wallingford, Oxfordshire, UK; 141-155.

Turpin O, Ferguson R, Johansson B. 1999. Use of remote sensing to test and update simulated snow cover in hydrological models. Hydrological Processes 13: 2067-2077.

Wallén CC (ed.). 1970. Climates of Northern and Western Europe, World Survey of Climatology, vol. 5 and 6. Elsevier Scientific Publishing Company: Amsterdam.

Witmer U. 1984. Eine Methode zur flächendeckenden Kartierung von Schneehöhen unter Berücksichtigung von relievbedingten Einflüssen. Geographica Bernensia 21: Geographisches Institut der Universität Bern: 91-138. 